\title{
Implementing an Instructional Design on Intercultural Communicative Competence (ICC) With Foreign Language Students Aimed at Joining the Corporate World
}

\author{
Héctor Manuel Serna Dimas ${ }^{1}$ \\ ${ }^{1}$ Faculty of Humanities and Social Sciences, Universidad EAN, Bogotá, Colombia \\ Correspondence: Héctor Manuel Serna Dimas, Universidad EAN, Calle 79 \#11-45, Bogotá, Colombia.
}

Received: January 8, 2019 Accepted: February 10, 2019 Online Published: February 12, 2019

doi: 10.5539/elt.v12n3p161 URL: https://doi.org/10.5539/elt.v12n3p161

\begin{abstract}
This study intends the validation of an instructional design on intercultural communicative competence (ICC) in the beginning levels of German, French, Italian, Portuguese, and English in the Modern Languages program at EAN University in Colombia. The design constituents: language integration, oral production, fieldwork activities, and a product/project gravitated around thematic units. The faculty application of the design is evidenced through annotated lesson plans together with the rationale for their classroom decision-making. The results indicate that an instructional design on intercultural communicative competence offers teachers and students a framework whose components acknowledge the participants' diverse views and promote an intercultural learning environment in both relational and interpersonal terms.
\end{abstract}

Keywords: instructional design, interculturality, communicative competence

\section{Introduction}

Universidad EAN is a Colombian university with undergraduate degrees in engineering, finance, business management, international business, economics, modern languages, and cultural management. All university programs are oriented towards goals such as entrepreneurship and sustainability. Moreover, EAN professionals are meant to make their way into organizations where they can promote and implement such values. The modern languages program is no exception, and its professionals are educated to be part of the corporate world. In fact, the program mission determines that professionals in modern languages will develop entrepreneurial aptitudes that help them contribute to the economic and social growth of people and organizations both at local and international levels. These capacities will be obtained through their active participation in projects that promote multilingual/multicultural development. In sum, these professionals will be part of the corporate world where languages are fundamental in the areas of communications, translations, and international businesses.

This situation poses opportunities and challenges for both the faculty and the students in the program. On the one hand, it is an opportunity to view language learning removed from its expected views of mastering a linguistic system or its pedagogical implications which are more pertinent for language student teachers. It is also an opportunity to educate these language professionals to be part of the corporate world of languages such as English, French, German, Italian, Portuguese, and Spanish.

On the other hand, it is a challenge to educate these individuals in a world that is for the most part transnational which means that the workforce will have the characteristics of being both international and multicultural; therefore, these professionals must be taught languages from intercultural perspectives. Thus, the language learning process requires that these students develop interpersonal and relational skills which enable them to relate to people from different language and cultural backgrounds.

Another challenge is that most of this language learning happens in the classroom which demands from both the faculty and the students to devise innovative ways to take their language endeavors beyond the classroom. For example, the language learning situations must integrate research activities, language fieldwork, and computer-mediated activities so that students have a wide perspective on the complexities of learning languages in multilingual and multicultural settings.

Including the intercultural communicative competence as the basis of this research process lies in a series of 
questions that the languages faculty at EAN University have faced with the development of the communicative competence of their students in the program. Some of these questions have to do with the students' beliefs that their learning processes are based exclusively on the status of native speakers of several of their professors, which can lead to more stereotypical situations in the teaching and language learning processes. Moreover, language instructors often realize how difficult it is for students to think of their native language and culture as contributions to build learning in other languages and cultures. Being able to relate languages and cultures is one of the essential elements to advance in deepening knowledge processes and the assumption of both attitudes and critical positions in one's own understanding and that of the "other" (Serna Dimas, Quaroni, Treuholz, Berlincourt, Franco, \& Sachett, 2016).

This research project has been developed in a series of phases which have aimed at establishing an intercultural language teaching perspective of foreign languages in the Modern Languages program at EAN University. The first phase of the project concluded with the definition and operationalization of intercultural communicative competence in the classroom through action research projects in courses of German, Italian, French, English, and Portuguese. The second phase was oriented towards the formulation of the components of an emerging instructional design in intercultural communicative competence that could be used by the professors of the different languages as a common teaching framework. The present third phase intends the validation of the instructional design in the beginning levels of German, French, Italian, Portuguese, and English. The professors integrate the components of the instructional design in their courses. In this phase, the extent of the application of the instructional design regarding the planning and implementation of teaching processes by these professors is considered.

The instructional design on ICC revolves around thematic units that are supported by four central elements from which the tasks of classroom planning, implementation, and evaluation must be arranged. The specific elements of the instructional design are 1) integration of communicative skills, 2) emphasis on oral production, 3) fieldwork research activities developed by students, 4) formulation and execution of a product/project aimed at the consolidation of learning. See Figure 1.

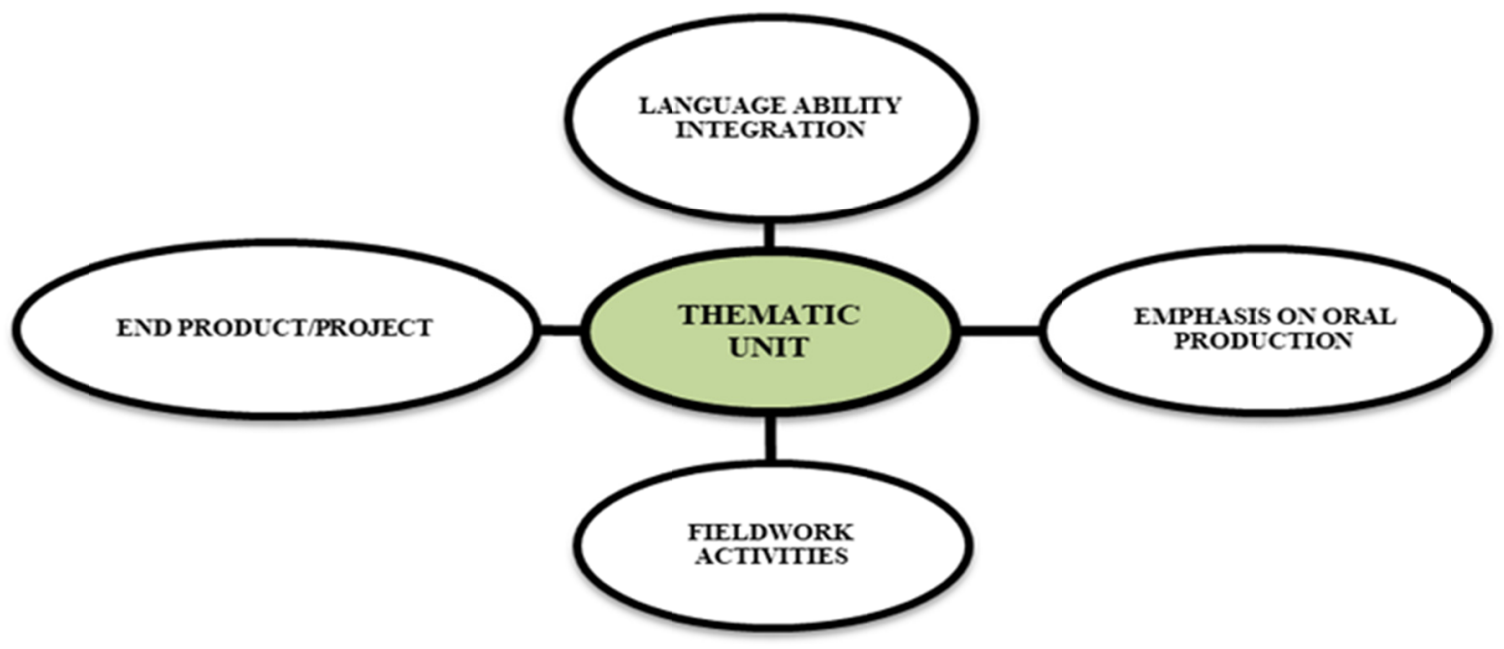

Figure 1. Instructional Design on Intercultural Communicative Competence

Source: Serna Dimas, H. M. (2017). Instructional Design on Intercultural Communicative Competence at Universidad EAN.

The research question generated in accordance with this third phase of the research project was the following:

To what extent is the intercultural communicative competence (ICC) in the teaching of foreign languages evidenced by the implementation of an instructional design centered on thematic units whose circling components are: the integration of communication skills, the emphasis on the development of oral skills, as well as the inclusion of fieldwork activities, and the completion of a product / project intended to consolidate learning? 


\section{Instructional Designs in Language Teaching and Learning}

The first element in this theoretical framework is the concept of instructional design and the reason it must become a fundamental part of an attempt to work on developing students' intercultural communicative competence in a foreign language setting. The idea of design takes into consideration a way to do something; it also demands a procedure, protocol, or at least a series of steps. Designs are meant to provide a wide-angle perspective on how to go about teaching and learning. Nation and Macalister (2010), for example, consider that the curriculum design process requires knowledge of aspects such as the environment, needs, and principles that gravitate around goals which are largely defined by the content, the format, the presentation, and its evaluation in terms of both monitoring and assessment (p. 3).

Instructional designs have been used in environments where learners need to become proficient in languages that are not their native. In other words, these languages are their second, third, or even foreign. Some of these models come from bilingual education: CLIL (Marsh, 1994); CALLA (Chamot \& O' Malley, 1994); SIOP (Echevarria, Vogt, \& Short, 2000). The above designs share that they all take into consideration the learners and their needs in terms of both their language and cognitive development; these two aspects have made them popular and have contributed to their spread and success in various scholarly settings.

In regard to interculturality, Lee, Poch, Shaw, and Williams (2012) suggest pedagogical frameworks that take into consideration a variety of aspects such as the curriculum and the instructional practices whose goal is to promote students' diversity. Intercultural language projects are successful if they promote diversity which in turn stimulates engagement as students will find a legitimate place to voice their views in what the language courses are about. The inclusion of culture in language teaching requires a framework that allows learners to understand its central role in language learning. Moeller and Faltin Osborn (2014) summarize some of these frameworks. For example, Byram's (1997) proposal of intercultural communicative competence based on knowledge, skills, and attitudes; Deardoff's (2002) model that pays special attention to aspects such as the learner's attitudes towards language and culture, and Borghetti's (2011) teaching framework that combines both cognitive and affective processes, and the establishment of a classroom that behaves as a community.

The design proposed in this study advocates the relationship between language and culture. In our attempt to figure out this relationship, the views of Kumaravadivelu (2008) are considered since he conceptualizes the connection of languages and cultures as a process that ranges from assimilation, pluralism, hybridity, and realism (p. 4). This last perspective is the one that he finds more encompassing with what is happening with the present globalization times of languages, cultures, and peoples. Kumaravadivelu defines the premise of cultural realism as:

"A 'web of interlocution' that is effectively challenging the traditional notions of identity formation of an individual or of a nation. This development is plunging the world in a creative as well as chaotic tension that both unites and divides people. It is also resulting in an unintended and unexpected moment toward tribalization that contributes to an increase in ethnic, racial, religious, and national consciousness." (p. 158).

Cultural realism provides a new and more challenging setting to enact language teaching and learning. In fact, Kurmaravadivelu advances some pedagogic principles which he describes as a series of shifts:

“a) From target language community to targeted cultural community, b) from linguistic articulation to cultural affiliation, c) from cultural information to cultural transformation, d) from passive reception to critical reflection, e) from interested text to informed contexts (p. 172).

Kumaravidelu's (2011) principles are worth examining against the context of prospective Colombian language professionals whose attempts at learning languages such as English, French, German, Italian, and Portuguese take place within the boundaries of the classroom. Furthermore, these languages are foreign in the country whose official language is Spanish. The above situation shows that it is not enough the sheer presence of native speaking instructors, the use of the latest commercial textbooks, or even the state-of-the-art technology to guarantee the enactment of intercultural teaching and learning.

This environment requires a teaching framework that provides relevant contexts and more importantly opportunities where teachers and learners experience intercultural language projects that cater to both language and culture learning in both relational and interpersonal terms. In sum, an instructional design that places teachers and students as legitimate speakers whose emergent relationship is not exclusively mediated by the bureaucracy of the classroom in terms of lessons, textbook activities, or tests.

The framework should promote a learning environment where the integration of linguistic abilities such as vocabulary and grammar need to be addressed together with the provision of opportunities to create language 
projects from a variety of sources. Moreover, there must be a concerted place where the use of videos and podcasts happen along with readings or writings to make sense of both language and culture by means of active student participation through oral interaction.

Kimber, Pillay, and Richards (2002) examine the role of teachers in a world that demands several competences such as the digital in computer-mediated settings. These new learning conditions confirm the need for designs that integrate these perspectives. They quote the work of the New London Group (200) which proposes a design with six elements "(linguistic, visual, audio, gestural, spatial and multimodal), and four associated components of pedagogy (situated practice, overt instruction, critical framing and transformed practice)." (p. 162). These scholars also consider that the notion of design invites teachers to become creators of classrooms practices specifically tailored to fit the teaching context and the students' realities, which are pervaded by computer-mediated experiences.

\subsection{Thematic Units}

Instruction around thematic units has been around for several years, and it continues to be a valid proposal from various camps since it promotes a view of learning that is focused on making sense of a topic from a variety of perspectives through processes of thoughtful integration. In terms of language learning, thematic units aim at giving students several encounters with language information through a variety of channels.

Zull (2002) provides examples from brain research and learning which demonstrate how integration happens in the brain; he asserts that there is always a brain cycle when people process sensory input to know and learn about the world around them. The cycle begins in the sensory cortex to the back integrative cortex and frontal integrative cortex and then to the motor cortex to end in the sensory cortex again (p. 23). He provides an example of language processing which he summarizes as follows:

"1. Hear words or see words = concrete experience

2. Remember related words, images, or ideas $=$ reflection

3. Generate new words or ideas $=$ abstraction

4. Speak or write new words or ideas $=$ active testing

5. Hear or see new words and teacher's response $=$ new concrete experience" (p. 23).

The above explanation on how the brain processes stimuli supports the need to design and prepare class sequences that resemble such processes as it was shown in the example. Zull invites teachers to consider these brain cycles when they plan and perform their teaching.

In the field of Content-Based Instruction (CBI), Grabe and Stoller (1997) quote the work of Mohan (1986) and Grabe (1995) who consider that one of the goals of thematic unit instruction "is to give students multiple opportunities to work with coherently developed sets of content resources and to revisit that information from a variety of perspectives, including exposure to visual representations and information.” (p. 11).

\subsection{Language Ability Integration}

Roegiers (2010) regards integration in pedagogy as a triad of concepts namely "interdependence, coordination, and polarization". (p. 30) Interdependence is the work of some related concepts that create a system based on the functional relationships of its many parts. Coordination has to do with how systems of ideas or concepts work in congruence. Finally, polarization refers to how systems are set in motion as meaning-making devices.

The planning of classes in terms of listening, speaking, reading, writing together with vocabulary and grammar should have the same thread that always connects them. This connectivity guarantees that students have constant exposure to the topics proposed in the unit in terms of both language and content. Furthermore, these topic activities engage students in events whose purpose is to reflect on how their language learning responds to such systematicity which is evidenced by the students' sense of accuracy and fluency in their language production.

This idea of advancing language teaching-learning processes by integrating language and communication skills is based on the students' attention to the construction of meanings beyond the concern for the ways in which these meanings are expressed. Kagan (1995) states that a process of second language acquisition is heightened to the extent that learners receive linguistic inputs whose nature is clear, appropriate to the development of the learners, repeated, and accurate (p. 1). Regarding reiteration, Kagan adds that this repeated exposure of linguistic forms and meanings from different sources facilitates the internalization process beyond a process of partial or short-term memorization of these ideas. 
Another important aspect to consider in this process of teaching preparation with an integrative perspective has to do with the apprentices' language development. Prabhu (1987) and Widdowson (1990) cited by Kumaravadivelu (2006) expressed their criticisms of the idea that knowledge of a language is linearly based on the study and management of fragmented units in a cumulative process. These scholars affirm that language learning is holistic and cyclical with some points of transition of parallel systems of linguistic configuration. (p. 141).

In sum, Kumaravadivelu asserts that in real terms, the production of apprentices can differ from the learning sequence and is in turn different from the teaching sequence. This conclusion seems to indicate that it is necessary to move towards an alignment between teaching, learning, and student production, which once again emphasizes the need to integrate language teaching and learning.

\subsection{Oral Production}

One of the key aspects in the language learning process is the promotion of the students' oral production so that they can gradually build discursive aspects that ultimately determine both their learning and language learning proficiency.

Garbati and Mady (2015) traced some of the most important research journals in the field of language teaching. From this exercise, the researchers extracted a series of strategies that were mentioned frequently in these investigations. The researchers talked about practices such as the explicit teaching of oral skills, scaffolding activities to provide oral production strategies, the provision of authentic communication spaces, improvised and planned oral presentations, use of tasks, fluency activities, activities of questions and answers, role-plays as well as activities in which students are counted for the evaluation and feedback of their production (pp. 1767-1768).

The conclusions of this review of the research in oral production in the second language, as well as the practices outlined above, agree with the approaches of theorists such as Gibbons (2007) who states, "that instructional designs adopted by teachers affect the quality and the effectiveness of the learning context" (p. 1768).

On a study on the nature of oral abilities in a foreign language context, Saito and Hanzawa (2016) wanted to test the effectiveness of foreign language instruction on students' oral abilities in terms of oral features such as prosody. Their results showed that there were external factors such as students' language exposure and aptitude that influenced the students' oral development. In fact, they asserted that the students' oral performance was heightened by their contact with the language outside class with a variety of other language resources.

Finally, the research and the classroom practices derived from these studies have as a common denominator a critique of the visions that one can take a single look and a single measure that can be applied to an entire population. Language students at EAN University may come from the same language and cultural background; however, there is still diversity in them which calls for language pedagogies that foster interaction so that this diversity nurtures both language and culture learning. Lee, Poch, Shaw, and Williams (2012) consider that there is a need for an intercultural pedagogy that promotes such interactions:

"As students engage with one another and encounter differences in their fellow students' perspectives and epistemologies, it can at first be challenging for them to generate active dialogue or to reach productive consensus. Facilitated, purposeful opportunities to interact provide students with experience communicating, listening, and negotiating across complex cultural, experiential, and epistemological perspectives." (p. 56).

\subsection{Students' Fieldwork Activities}

Students should become aware that they contribute with the input for the construction of concepts and subsequent learning that is generated from their classroom experiences. In fact, it is their experiences that make up most of what their language learning is going to be about. These contributions must be related to exploration, investigation, or expanding activities in relation to the class topics.

Byram (1997) defines fieldwork as "a pedagogical structure with educational objectives constructed by the teacher in consultation with students" (p. 68) One of the essential elements of this structure of work has to do with the development of learning skills in action in real time and with a great emphasis on interaction and whose ultimate goal is the contribution of students to the knowledge that is being generated in the classroom (p. 69).

The instructional design contemplates that these opportunities for interaction among language learners are increasingly in line with the principles of intercultural communicative competence in which the learners, according to Byram and Zarate (1994), bring with them a wealth of experiences as well as a socio-cultural identity constructed mainly in their $\mathrm{L} 1$ and $\mathrm{C} 1$ which empower them as mediators between cultures.

This last idea poses challenges to both the learners and their teachers. In the case of apprentices, intercultural 
communicative competence will be given by their ability to relate aspects of their L1 and $\mathrm{C} 1$ with respect to their L2 and C2 against which they must elucidate and resolve dysfunctions and/or conflicts. In the case of teachers, they must have the ability to discern aspects of their "native" linguistic competence that may have possible dysfunctions and/or conflicts with those of their students emerging competence.

\subsection{Learning Consolidation Product/Project}

Students can shape their learning to the extent that they participate actively in the construction of a consolidation activity such as the formulation and implementation of class projects. Kumaravadivelu (2008) asserts that one of the classroom strategies that are most conducive to promoting levels of cultural awareness among students is the development of exploratory projects in which students can test their knowledge of the topics they choose to develop. In the current scheme of world globalization and easy access to resources that provide information such as internet browsers, social networks, and applications, there is a challenge to guide students to overcome the superficial views of the information they locate in order to bring them to know these topics in depth from either a global perspective or a comparative look among languages and cultures.

This specific aspect of the design can be covered as class activities are structured into concrete learning products or short-term projects such as exhibitions, dramatizations, audiovisuals, and portfolio of documents, written works, web pages, podcasts, and research reports.

As it is seen from Figure 2, the thematic unit elicits a cycle whose entry point could be any of the communicative abilities. Nevertheless, many times students require vocabulary and grammar as the building blocks of language proficiency. That being said, the focus of the unit must be the theme and the meanings students will eventually come to generate as the lessons evolve into some sort of product or project in agreement with the thematic unit.

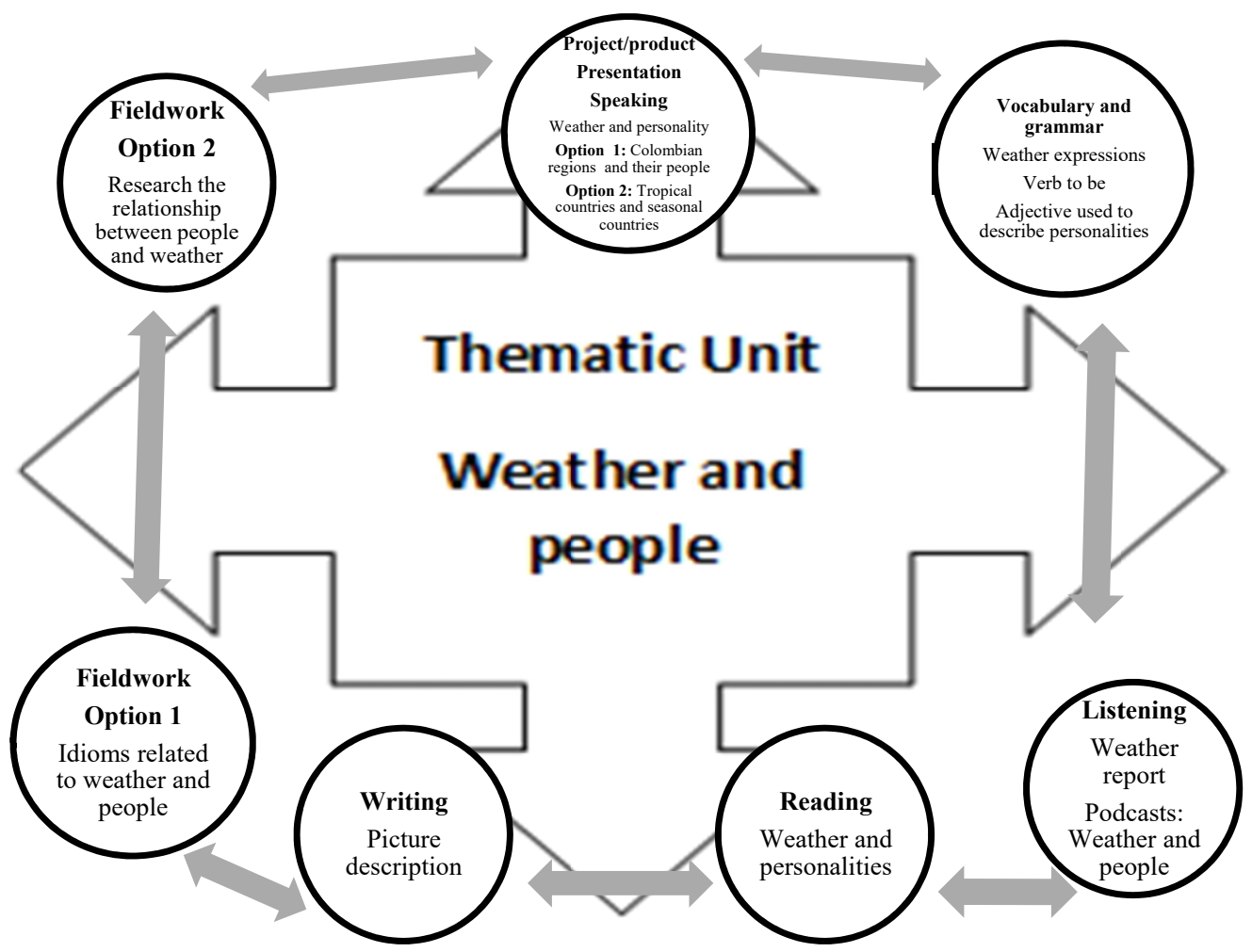

Figure 2. Instructional design in motion

Source: Serna Dimas, H.M. (2017). Instructional Design on Intercultural Communicative Competence at Universidad EAN.

\section{Methodology}

This study is mixed; it follows a sequential explanatory strategy (Creswell, 2003) which means that the collection and analysis of quantitative data will be followed by the collection and analysis of qualitative data. 
The quantitative data is based on the faculty completion of two annotated lesson plans as a checkup of the application of each one of the instructional components of the design.

The qualitative data will be based on the professors' rationale for the design application. Therefore, the analyses will have a hermeneutical vision whose purpose is to analyze the professors' decision-making based on their lesson planning and the subsequent rationale for changes or variations as the design components were set in motion. The role of hermeneutics is to develop understandings from the professors' implementation of the instructional design both as a whole and in its parts, which validate the notion of a hermeneutic cycle (Gadamer, 1989).

The interpretation of these teachers' decisions and their reasoning can be understood through the lens of teacher cognition. Borg (2003) refers to teacher cognition as "the unobservable cognitive dimension of teaching -what teachers know, believe, and think." (p. 81). He offers a comprehensive account of research on teacher cognition from three foci: cognition and prior language learning experience, cognition and teacher education, and cognition and classroom practice (p. 81).

For the purposes of this study, the perspective on cognition and classroom practice deserves attention since the analyses of teachers' knowledge, as they make decisions on their lessons, and as they depart from their plans, provides understandings on the implementation of the instructional design on intercultural communicative competence.

Borg's examination of teacher research shows that teachers have different reasons to account for their decision-making. However, the reasons they claim range from motivational aspects to classroom management issues. As for the reasons to depart from an original lesson, Borg found that teachers had one or some of the following reasons: years of experience in teaching, a question or unexpected issue arose, student factors such as discipline, or teachers' factors such as forgetting a class element (p. 94). Nevertheless, Borg sees these changes as legitimate since they show that teachers were trying to elucidate the articulation of two aspects of their teaching namely their pedagogical choices and the instructional context.

\subsection{Language Learning Theory}

The language learning theory that guides this study is the sociocultural theory which can be defined as a position that deliberately and decisively involves aspects of the historical, social, and cultural context of individuals (Johnson, 2009). These elements are fundamental if there is a proposal that promotes teaching and learning languages in an intercultural perspective; understanding interculturality: as the abilities that individuals from different languages and cultures display to relate to each other.

Johnson (2009) maintains that cognition in a sociocultural perspective occurs to the extent that learners engage in social activities which trigger a series of social and cultural relationships around systems of meaning together with the performance and interaction of these individuals. In conclusion, the researcher states that "cognitive development is the product of a process mediated by the interaction of social, linguistic, cultural, and contextual aspects." (p. 1).

Another central idea in sociocultural theory is the notion of language as a social practice. This conception maintains that the language is the main generator of experiences of different kinds, and it is the same language that allows individuals to be and participate in the world in a meaningful way. Johnson asserts that the linguistic perspective that is most consistent with this idea is the systemic functional linguistics of Halliday (1989), especially in his definition of understanding language as a semiotic system that gives individuals a series of linguistic options on which they decide according to the contexts, the activities, and the roles they assume according to their participation in communicative events (p. 45).

The role of language teachers in their interpretation of language as a social practice in the teaching and learning processes has to do with a process of awareness about the power of the language to generate meanings that deal with the creation of individuals in terms of both their personal identities and their roles as social beings.

Finally, language as a social practice in language teaching becomes real as far as these environments approach language use as a mediating element of the dialogical exercise that must exist among the participants of this process.

Johnson describes this process in the following way:

"The focus (language as a social practice) is not the correct use of a linguistic form or a communicative function, however, it is in the nature of the activities in which teachers and students are immersed and what they want to accomplish by these participants in these activities, and how the language and other cultural artifacts are used as 
tools of mediation in those activities." (p. 54).

\subsection{Participants}

Six professors (language coordinators) of English (EN), French (FR), Italian (IT), Portuguese (P), and German (G) implemented the instructional design in their courses. English contributed to this project with two professors. This faculty had studies in language pedagogy and were experienced in the teaching of their corresponding language. It is worth pointing out that not all these professors had participated in the previous two phases of the project as it was the case of the Portuguese, German, Italian, and one of the English faculty. However, they all took part in orientation sessions prior to the launching of the project. For example, they all participated in meetings where they exchanged their thematic unit proposal and had a say on the annotated lesson plan formats.

Table 1 provides information regarding the languages, thematic units, students' levels of proficiency, and the criteria the faculty used for the application of the design in terms of their lesson plans or their decision-making processes as the lessons evolved.

Table 1. Participants

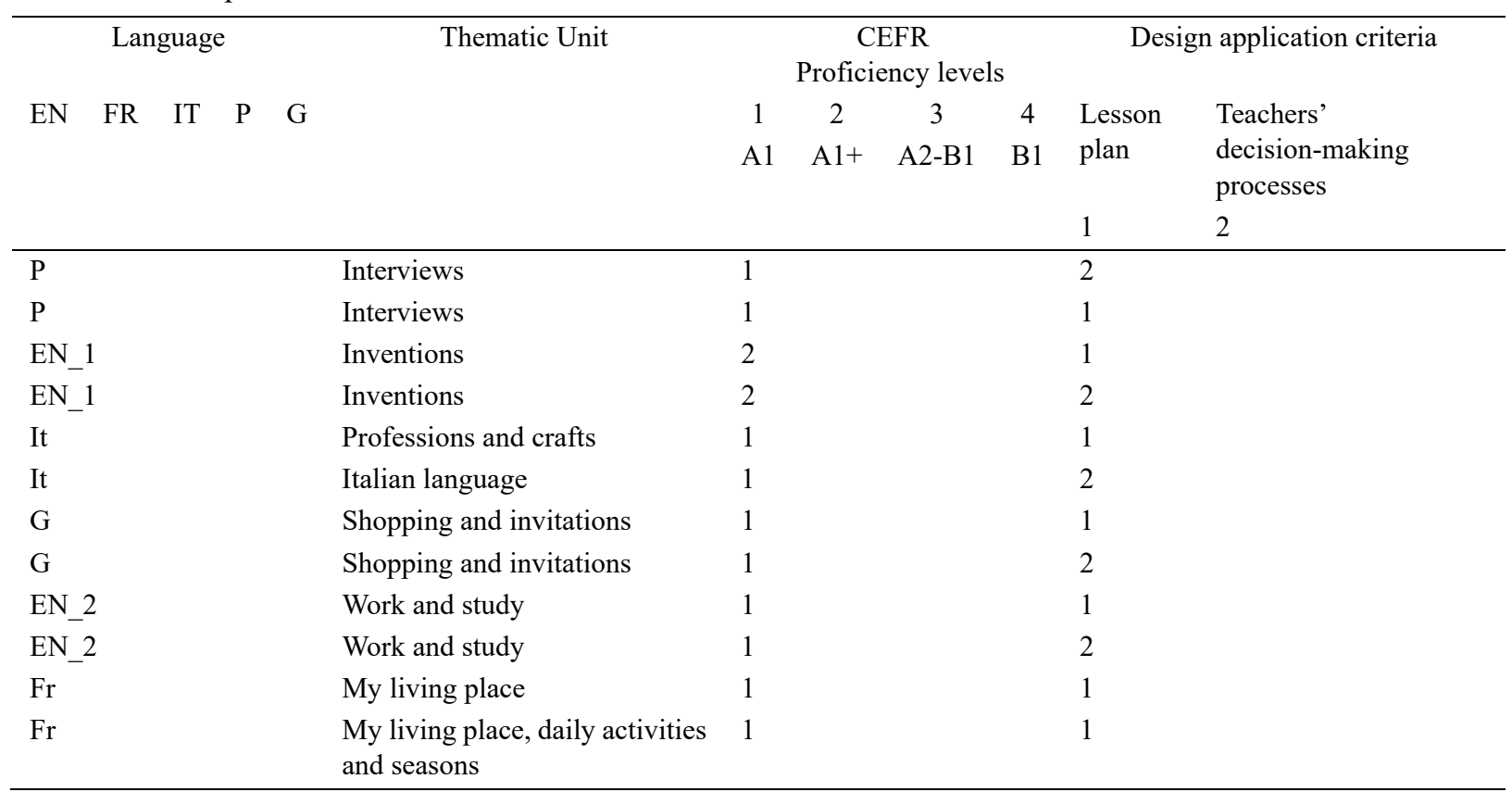

\section{Results}

The main goal of this study is to make sense of how teachers implemented the instructional design with their lesson plans as a framework and their correspondence with concrete classroom activities. By analyzing these circumstances, it can be determined the strengths and weaknesses of the proposal in order to make the necessary changes or adaptations so that the design eventually fits the program and more importantly the students'needs.

The six professors worked with levels 1 and 2 which means that these students were at the initial stage of their studies. All had thematic units except for the Portuguese professor who seemed not to have one. However, he worked on a semester-long project based on an interview with Brazilian businessmen in Colombia.

Each professor reported two annotated lessons plans, and the source of integration stemmed from either the lesson plan or the actual classroom circumstances. It is noticeable that the preferred pattern was 1 which means that the basis for integration was at first part of a planned lesson which then evolved as the professors introduced changes as the lessons progressed. See Table 1 .

The first design component is the purposeful integration of the linguistic and communicative skills to get the cycle started. Table 2 offers a more detailed description of how the integration took place. 
Table 2. Language ability integration

\begin{tabular}{|c|c|c|c|c|c|c|c|c|}
\hline \multicolumn{9}{|c|}{ LANGUAGE ABILITY INTEGRATION } \\
\hline Language & $\begin{array}{l}\text { There is } \\
\text { integration }\end{array}$ & Listening & Speaking & Reading & Writing & Vocabulary & Grammar & $\begin{array}{l}\text { There is an } \\
\text { emphasis on }\end{array}$ \\
\hline EN FR IT $P$ G & & & & & & & & Listening 1 \\
\hline & & & & & & & & Speaking 2 \\
\hline & & & & & & & & Reading 3 \\
\hline & & & & & & & & Writing 4 \\
\hline & & 0-No; & 0-No; & 0-No; & 0-No; & 0-No; & & Vocabulary 5 \\
\hline & 0 -No; 1 -Yes & $1-$ Yes & 1 -Yes & 1 -Yes & $1-$ Yes & 1 -Yes & 0 -No; 1 -Yes & Grammar 6 \\
\hline$P$ & 0 & 1 & 0 & 1 & 0 & 1 & 1 & 3 \\
\hline $\mathrm{P}$ & 1 & 1 & 1 & 1 & 1 & 1 & 1 & 2 \\
\hline EN_1 & 1 & 1 & 1 & 1 & 1 & 1 & 1 & 2 \\
\hline EN-1 & 1 & 1 & 1 & 1 & 1 & 1 & 1 & 2 \\
\hline IT & 1 & 1 & 1 & 1 & 1 & 1 & 1 & $1,2,5$ \\
\hline IT & 1 & 1 & 1 & 1 & 1 & 1 & 1 & 1.2 \\
\hline G & 1 & 1 & 1 & 1 & 1 & 1 & 1 & $2,3,4,5$ \\
\hline G & 1 & 1 & 1 & 1 & 1 & 1 & 1 & $2,3,4,5$ \\
\hline EN_2 & 1 & & & & & & $1,2,3,4,5,6$ & 2 \\
\hline EN_2 & 1 & & & & & & $1,2,3,4,5,6$ & $1,2,3,4$ \\
\hline FR & 1 & 1 & 1 & 1 & 1 & 1 & 1 & 2 \\
\hline FR & 1 & 1 & 1 & 1 & 1 & 1 & 1 & 2 \\
\hline
\end{tabular}

The Portuguese professor did not acknowledge the integration at first but reckoned it took place in some other moments of the class sequence. It is worth looking at the English_2 faculty whose planning seemed to indicate that the place of integration was for the most part around grammar. The German and Italian faculty placed their emphasis on several abilities at the same time. Unlike these faculty, the first English professor and the French focused on oral abilities primarily.

It was already established that there was ability integration which varied among the languages, so it is relevant to know the reasons professors had as they developed this component of the instructional design in their classes.

Table 3. Rationale for ability integration

\begin{tabular}{|c|c|}
\hline \multicolumn{2}{|c|}{ RATIONALE FOR THE INTEGRATION OF ABILITIES } \\
\hline $\mathrm{P}$ & "There was no total integration. I would say there was partial integration." \\
\hline $\mathrm{P}$ & "Through a research exercise project put into practice." \\
\hline EN_1 & $\begin{array}{l}\text { "Students investigate a discovery that is recognized in the student's context and that has a high impact in this } \\
\text { century. Based on that, they must present all the data related to the invention from the historical importance and } \\
\text { reason why they chose it. They make an oral presentation. For all that work, they must first think of the invention } \\
\text { or innovation. Then they investigate and create a vocabulary list. Later, each one writes the narrative of the } \\
\text { researched; and finally, a single written report is made in common and the oral presentation is made for group } \\
\text { discussion. }\end{array}$ \\
\hline EN_1 & "Each activity to be developed in class and this development involves at least one skill and that is a constant." \\
\hline IT & $\begin{array}{l}\text { "The class activities involve the use of each skill at different times. For example, reading aloud to analyze the } \\
\text { structures found, comment on the topic in groups, write a summary." }\end{array}$ \\
\hline IT & $\begin{array}{l}\text { "I try in each lesson the students, based on a theme, identify in a reading or an audio the vocabulary. We identify } \\
\text { the grammatical part, they discuss their ideas about the topic and if possible, write some sentences/ideas about } \\
\text { it." }\end{array}$ \\
\hline G & "Students read the catalogs of different supermarkets, discuss them, review the vocabulary, and create a dialogue. \\
\hline EN_2 & $\begin{array}{l}\text { "By appropriating the vocabulary in context and expressions required to analyze and write a resume; students also } \\
\text { interview a professional in real life." }\end{array}$ \\
\hline EN_2 & $\begin{array}{l}\text { "By appropriating the vocabulary in context and expressions required to analyze and write a resume; students } \\
\text { also interview a professional in real life." }\end{array}$ \\
\hline
\end{tabular}


Table 3 offers the justification for the ability integration which, according to the professors, happened when students were required to process information in one ability using another one; for example, using writing to make sense of listening. However, one of the English faculty had a perspective that was more encompassing with the instructional design cycle in Figure 2 where the abilities tend to overlap in terms of using one to build the other. That is, these students end project was a presentation about an invention which had started with gathering data, then the preparation of a vocabulary list, and a narrative as a precursor of the final oral presentation. This process included reading, vocabulary, writing, and speaking. It is important to emphasize that the thematic unit was the focus around which students had multiple encounters with the language. The second English faculty also viewed the use of the abilities in terms using the language to an end project where the abilities provided the linguistic and communicative background to be able to interview a professional.

The second element of the instructional design was oral production, and how this ability required special attention since these language professionals are to work in the areas of communication and translation in business settings where constant and immediate language interaction is a must.

Table 4. Oral production

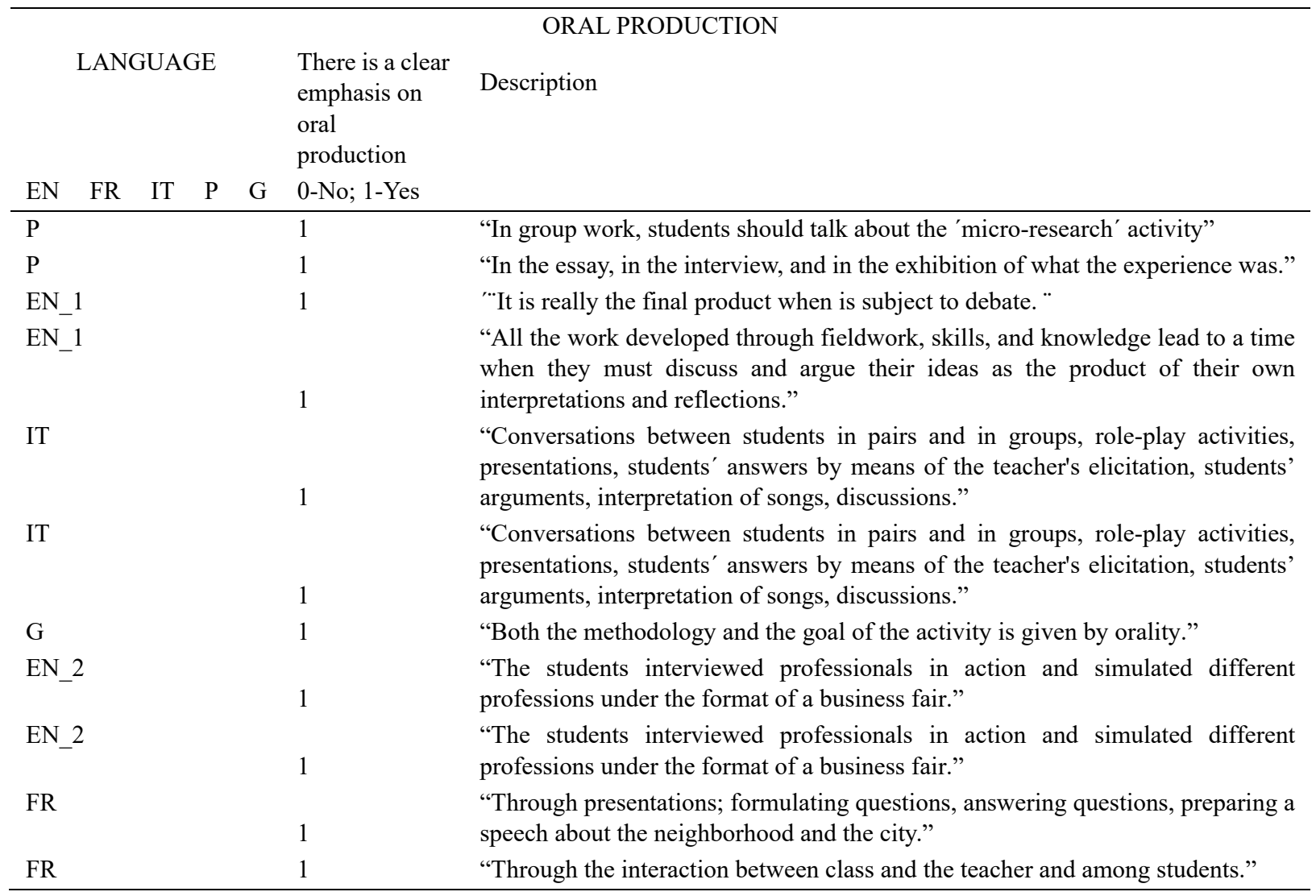

Table 4 shows that there was such an emphasis on oral production on the development of each one of the thematic units designed by the language professors. Most of the activities that took place matched what Garbati and Mady (2015) found in their review of oral abilities research in the classrooms in terms of role-plays, presentations, and interactive activities.

A close look at the description provided by the faculty revealed some aspects that are worth analyzing in terms of the emergence of oral production in students. First, some professors were more detailed about the variety of oral communication formats. Second, some of them understood the ability as part of the product whereas others considered that students needed multiple encounters on a variety of formats to develop their oral production. Last, 
some professors geared their efforts towards having students ready for a presentation, dialogue, or some planned interaction; others left the advent of speech as something more open in terms of conversations or the participants' exchanges.

Fieldwork was the next element to be analyzed against the backdrop provided by the lesson plans. Two essential ideas emerged regarding the work on thematic units. First, students carried out fieldwork activities on their own, and second, these activities had a relationship with the class contents which could relate to either a language issue such as vocabulary and grammar or the specific content addressed in the thematic unit.

Table 5. Fieldwork

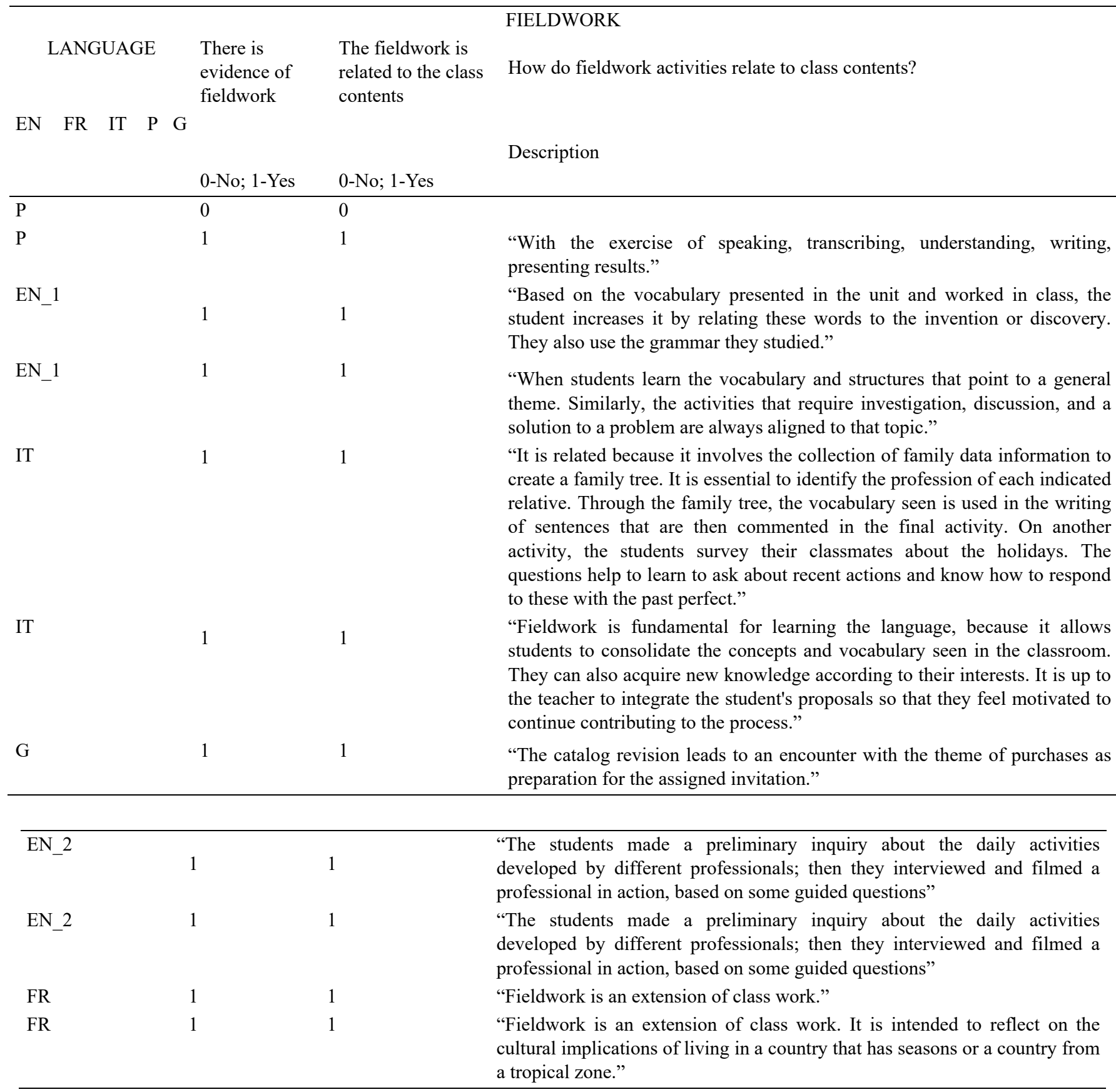

The faculty seemed to agree that fieldwork was an extension of classwork since students had to work on language concepts to deepen their understanding of the class topic or had to find information to help them prepare for the end of the unit project or product. However, the Italian professor had a different view of 
fieldwork since she considered that there was a lot of potential for students to pursue their own interests with activities that were meant to be done outside the class.

The last component of the instructional design was the end of the unit product or project. The professors described concrete projects that ranged from deliverables as part of a research project to the actual preparation of activities intended to be presented in front of an audience as a presentation or a classroom fair.

Table 6. End of the unit product/project

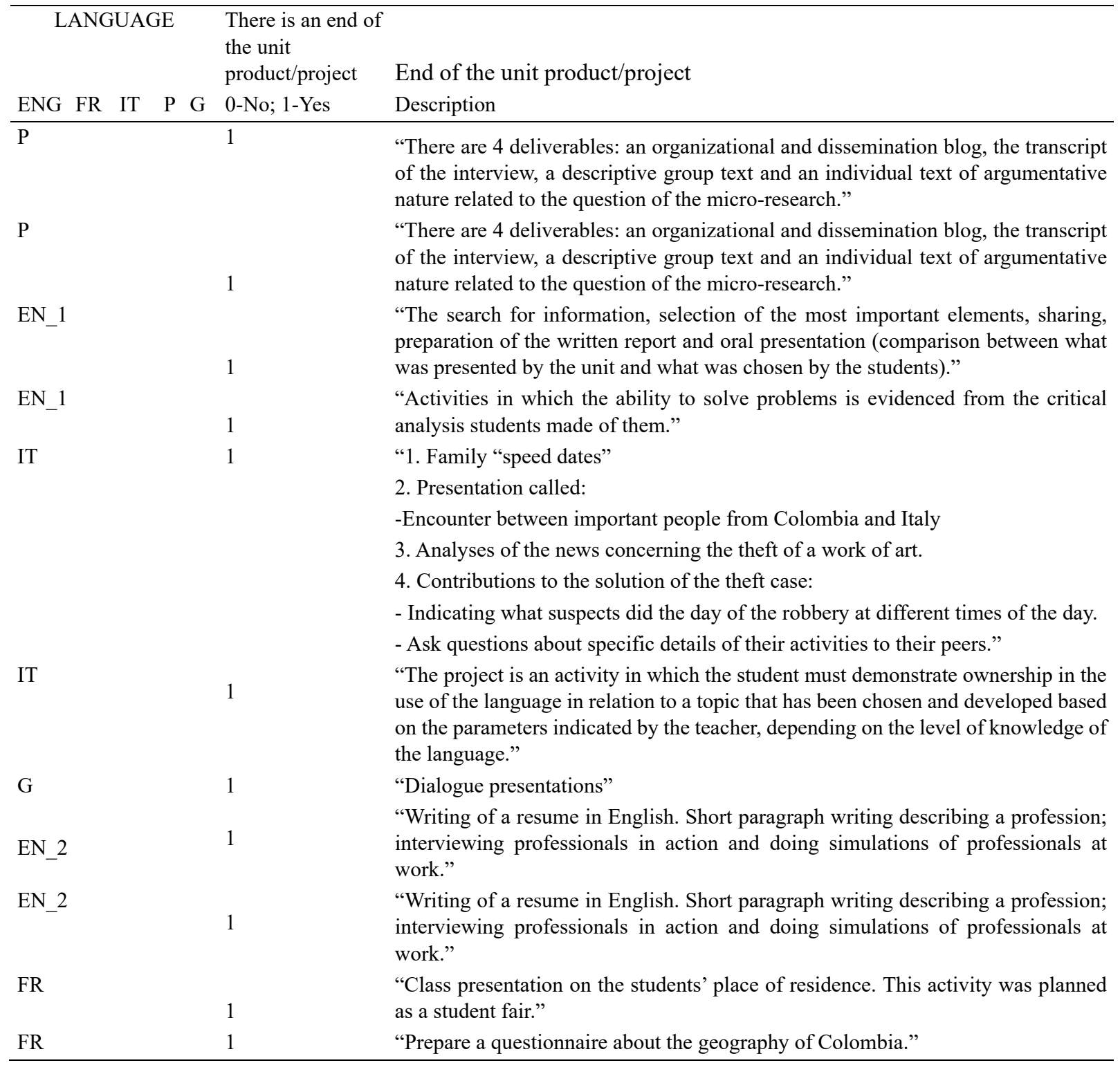

These products/projects in words of all the professors were meant to show students ownership over their learning, and many of them were thought of as projects of interculturality where students had to try to put in relation their $\mathrm{L} 1 / \mathrm{C} 1$ and their $\mathrm{L} 2 / \mathrm{C} 2$. For example, both the Italian and French instructors conducted activities in which students had to compare cultures.

The evidence provided by the professors in their lesson plans showed that they used the language for purposes other than the manipulation of vocabulary or other linguistic forms. The language was used with a social purpose aimed at purposeful communication based on the focus of the thematic unit. For example, the research and subsequent presentation of an invention in one of the English classes.

The above analysis of the annotated lesson plans and the application of the instructional design in interculturality 
requires a more detailed understanding from the professors' perspectives. What follows is the elaborations of these faculty based on their answers to three specific questions:

$>\quad$ What do you consider to be the place of the instructional design from the didactics of your language?

$>$ Based on your experience, what do you think is the relevance of an instructional design in the university setting?

$>$ How was interculturality evidenced in the implementation of the instructional design?

\section{Portuguese}

The Portuguese professor did not recognize that there was an instructional design; he viewed the experience more in terms of a sequence of activities. He was critical of the idea of bringing up the concept of instruction or instructional design in a university setting that seemed to be devoted to a more universal idea such as education. He also had a view of interculturality that had to do with worldviews among a number of other things. Thus, he did not see any of that in the semester-long project of aspiring Portuguese language students interviewing Brazilian businessmen doing business in Bogotá, Colombia.

English

Unlike the Portuguese professor, the EN_1 faculty considered that the instructional design allowed him to fully develop the thematic unit. He also considered the design relevant since it helped him fulfill the aims of the program in terms of giving students opportunities to work with English in relevant professional environments. The intercultural view in the design, according to this faculty, was accomplished in the sense that he could strike a balance between the world of the textbook and the world outside the textbook which was for the most part base on their students' experiences where they could relate aspects of their L1/L2 and C1/C2.

The EN_2 professor also mentioned both the development of critical thinking and inquiry strategies that need to be part of language learning processes oriented towards the students' successful participation in the workplace.

\section{Italian}

The Italian professor regarded the place of the instructional design in the didactics of the language as the connection between language and culture that should guide the teaching of languages. The Italian professor attributed the relevance of the design to the professor and the lesson plan preparation. In regard to the place of interculturality in the design, this professor pointed out the moments where both cultures were viewed on an equal basis.

\section{German}

The German professor considered that the principles of the communicative approach were met as the design provided a structure. Moreover, the professor viewed the relevance of the design in terms of the precision of class planning and the efficiency of skills articulation. Interculturality emerged when students had opportunities to depart from the material provided and compare it with cultural aspects that were not precisely their own.

\section{French}

Finally, the French professor asserted that there was a relationship between the design and the didactics of her class; she emphasized the fieldwork component as the most prominent when giving students the chance to work on cultural aspects. This professor saw the benefit of the design in terms of a guide for both teachers and students; however, she felt this could become very repetitive. With respect to the last question, the professor reckoned interculturality was addressed in topics that challenged not only the students' perspectives in terms of the Colombian and French culture but also the students' view of their own culture.

\section{Discussion}

The language professors applied the concepts of an instructional design to integrate the intercultural communicative competence of students at Universidad EAN. Their work became evident through the completion of two annotated lesson plans with their rationale in the application. The professors planned their lessons according to the proposal, and they reckoned lesson planning and following the design provided a structured and efficient administration of the thematic unit.

In regard to ability integration, they all complied with the proposal; however, the integration did not take place as envisioned in the design. Some of the faculty considered that one ability led naturally to the other; nevertheless, ability integration is more about creating conditions for students to process language concepts through constant exposure by different means and with a focus in mind, which is usually an oral production activity. In short, students will be able to make a word part of their discourse if they have heard this word, read about it, used it 
with a purpose in writing and uttered it in a speaking exchange appropriately. By doing this, students will have better chances to internalize language and ultimately produce it in a new context as their own discourse.

Oral production was the next aspect of the design, and it was addressed by all professors. It is important to point out the variety of formats for speaking activities which substantiate the idea that oral production is enacted through a variety of means according to both situations and contexts where language interaction happens. Although there were opportunities for oral production, some professors directed their efforts to shape the language production in attention to the end of the unit product/project. On the other hand, other faculty was more focused on how oral interaction emerged without a preconceived format in mind. However, the first alternative towards oral production seems to be more appropriate for the beginning levels of proficiency demonstrated by the learners.

Fieldwork was also part of the faculty lesson plans, and it matched the aims of the project in terms of having students bring input to the class in terms of exercises, external sources, or research. The professors' rationale also matched the idea that students needed to reflect upon the class contents beyond the class activities or the textbook ideas in order to contribute to the class contents by adding their personal perspectives.

The end of the unit product or project complied with two criteria; on the one hand, students had to carry out activities to consolidate some unit concepts, and on the other hand, students had to do a class presentation as a result of the contents and the fieldwork activities.

The faculty perspectives after their design application seemed to indicate that the design imposed a class structure which became evident in the lesson plans. They also acknowledged the fact that the design components such as fieldwork encouraged students' engagement and the promotion of their critical thinking skills which are fundamental to display the intercultural communicative competence.

In terms of the last three questions regarding the place of the instructional design in the faculty's teaching perspectives in both their pedagogy and didactics, it stood out as a common aspect the idea of relevance which echoes Van Dijk's (2009) definition of relevance of contexts not as "'objective' social properties of a situation, but a subjective definition of a situation." (p.4) In other words, context relevance has to do not only with some external elements that contribute to defining a situation but also the way speakers through their interaction agree on the nature and further development of such a situation as the communicative processes take shape and evolve. This aspect is very pertinent in foreign language teaching settings where professors need to figure out ways for the so-called "communicative activities" to outlive the immediacy of the textbook exercises. The best means for this to happen is to include students' lived experiences and the teachers' provisions for the students to voice them which will validate the idea of meaningful communication in a class.

The faculty considered that working from lesson plans allowed to implement the design more easily although there were some caveats regarding the understanding of ability integration in the actual application of the design.

The faculty also acknowledged the fact that the nature of the units and their end products provided a place for interculturality to emerge as part of the class contents and their further development. Nonetheless, the Portuguese professor conferred a different perspective to his class experience which could be accounted for, as it was mentioned earlier, the lack of correspondence between the lesson plans and the class actions which motivated a mismatch between the professor pedagogical views and his instructional context.

Interculturality does not only happen when people try to put in touch different or foreign languages and cultures. In fact, episodes of interculturality can also happen with students who share the same language and cultural background. These moments of interculturality may as well occur with other issues such as the social, and economic background of students as it was expressed by the French instructor.

The above situation restates the need for language learning projects that take into consideration theoretical perspectives such as sociocultural theory as it considers the individual immersed in historical, social, and cultural circumstances that will contribute to his becoming as an intercultural speaker.

\section{Limitations}

Even though there was an important effort to develop a coordinated implementation of the instructional design, some aspects still need to be evaluated. First, the language faculty integrated both the linguistic and communicative skills; however, such integration did not match the design cycle as it was projected for all the languages. Nonetheless, there was a clear idea among all the faculty that fragmented teaching was a hindrance for language learning processes. Second, there has to be more work and research around the idea of oral production, and how it is enacted in classroom settings. It seems that there is a competing view between the use of oral abilities as a means or as a product of language learning. Third, fieldwork requires to be regarded as the 
space that students create for themselves in order to propose and develop autonomous work on different aspects of the thematic units. Finally, language planning needs to be reconsidered to the light of concepts such as design, and more importantly the creative demands that such a concept entail.

\section{Conclusions}

The first aspect to conclude from this study is the need for designs that not only provide a framework to integrate interculturality in language lessons but also take the learner as essential to the process since each one of the design components is meant to have the learners as protagonists of the thematic unit.

The second conclusion that stems from this study is the relevance of promoting language learning through the lens of thematic units as they allow classroom participants to guide their efforts towards a product or project to consolidate learning. In fact, these products or projects have the quality of creating or recreating language as new since this language is the students' own production rather than the parroting of textbook exercises.

In regard to the professors' understanding of the model, three aspects emerged as important. First, it is required to have more exchanges among the faculty around the relevance of the model and its implementation. Second, it is also required to develop more work and a research agenda around ability integration and its impact on foreign language learning. Finally, research on teachers' cognition take into account the three foci already cited by Borg (2003) in terms of language learning experience, teacher education, and classroom practice; however, I think they need to work as a coherent set to help teachers make sense of their work especially when the classroom constantly provides unexpected or new circumstances that demand from teachers to reframe their practices.

It is also interesting to reflect upon the project, and how much of its foundations reflect the professors' pedagogical ideas and classroom practices. Furthermore, it is thought-provoking to develop further research on how language professors make sense of interculturality and its realization in their classroom practices.

Interculturality does not happen in class as a default result of language teaching and learning. In fact, the inclusion of interculturality requires frameworks that are built on perspectives on language learning and the professors' enactment in their classes via careful planning and rigorous understanding of how languages and cultures operate and interact in language learning processes.

Finally, at the heart of all the proposals reviewed for implementing language and culture learning lies the central idea of enacting language learning processes in relational terms beyond the routine teacher and student classroom relationship. Kramsch (1998) claims that language students have the privilege of becoming intercultural speakers, and this privilege "must be accompanied by an increased sense of personal and individual responsibility in the use of words and in the ownership of meanings." (p. 31). As a result, it is the teacher's job to promote language learning in the students' own words which ultimately unveil the complexity and richness of culture. In fact, language teaching in foreign contexts does not advance if teachers make the context more foreign by not giving a proper place to what students have to say about their views on both language and culture learning from the diversity of their own experiences.

\section{References}

Borg, S. (2003). Teacher cognition in language teaching: A review of research on what language teachers think, know, believe, and do. Language Teaching, 36, 81-109. https://doi.org/10.1017/S02614448803001903

Borghetti, C. (2011). How to teach it? Proposal for a methodological model of intercultural competence. In A. Witte, \& T. Harden (Eds.), Intercultural competence: concepts, challenges, evaluations. (pp. 141-159). Bern Switzerland. Peter Lang.

Byram, M. (1997). Teaching and Assessing Intercultural Communication Competence. Clevendon: UK. Multilingual Matters.

Byram, M., \& Zarate, G. (1994) Definitions, objectives and assessment of socio-cultural objectives. Strasbourg: Council of Europe.

Chamot, A. U., \& O' Malley, J. M. (1994). The CALLA handbook: Implementing the cognitive academic language learning approach. White Plains, NY: Addison Wesley Longman.

Creswell, J.W. (2003). Research Design: Qualitative, quantitative and mixed-methods approaches (2nd ed.). Thousand, Oaks, Ca: USA. SAGE Publications.

Deardorff, D. K. (2006). Identification and Assessment of Intercultural Competence as a Student Outcome of Internationalization. Journal of Studies in International Education, 10, 241-266. https://doi.org/10.1177/ 1028315306287002 
Echevarria, J., Vogt, M. E., \& Short, D. (2000). Making Content Comprehensible for English Learners: The Journal of Education and Training Studies, 1(2). Boston, MA: Allyn \& Bacon.

Garbati, J. F., \& Mady, J. C. (2015). Oral Skill Development in Second Languages: A Review in Search of Best Practices. Theory and Practice in Language Studies, 5(9), 1763-1770. https://doi.org/10.17507/tpls.0509.01

Gadamer, H. G. (1989). Truth and Method (2nd ed.) J. Weinsheimer, \& D. Marshall (Trans.). New York: USA.

Gibbons, P. (2007). Mediating Academic Language Learning Through Classroom Discourse. In J. Cummins, \& C. Davison (Eds.), International Handbook of English Language Teaching (pp. 701-718). New York: USA. https://doi.org/10.1007/978-0-387-46301-8_46

Grabe, W. (1995). Discourse Analysis in Reading Instruction. In T. Miller (Ed.), Functional Approaches to Written Text: classroom applications. Paris. TESOL, France.

Grabe, W., \& Stoller, F. (1997). Content-Based Instruction: Research Foundations. In M. A. Snow, \& D. M. Brinton (Eds.), The Content-Based Classroom: perspectives on integrating language and content. White Plain, N.Y: USA. Longman.

Halliday, M. A. K. (1989). Spoken and Written Language. Oxford: UK. Oxford University Press.

Johnson, K. E. (2009). Second Language Teacher Education: A sociocultural perspective. ESL \& Applied Linguistics Professional Series. New York, NY: USA. Routledge. https://doi.org/10.4324/9780203878033

Kagan, S. (1995). We Can Talk cooperative learning in the elementary ESL classroom. CAL Digest. Retrieved from http://www.cal.org/resources/digest/kagan001.html

Kimber, K.; Pillay, H.; Richards, C. (2002). Reclaiming Teacher Agency in a Student-Centred Digital World. Asia-Pacific Journal of Teacher Education, 30(2), 155-167. https://doi.org/10.1080/13598660220135667

Kramsch, C. (1998). The privilege of the intercultural speaker. In M. Byram, \& M. Fleming (Eds.), Language Learning in Intercultural Perspective: Approaches through drama and ethnography. Cambridge Language Teaching Library. Cambridge: UK. Cambridge University Press.

Kumaravadivelu, B. (2006). Understanding Language Teaching: From method to postmethod. ESL \& Applied Linguistics Professional Series. New Jersey, NY: USA. Lawrence Earlbaum Associates, Publishers.

Kumaravadivelu, B. (2008). Cultural Globalization and Language Education. Yale: USA. Yale University Press.

Lee, A.; Poch, R.; Shaw, M.; Williams, R. (2012). Engaging Diversity in Undergraduate Classrooms: A pedagogy for developing intercultural competence. In K. Ward, \& L. E. Wolf-Wendel (Eds.), ASHE Higher Education Report. Wiley Online Library.

Marsh, D. (1994). Bilingual Education \& Content and Language Integrated Learning. In International Association for Cross-cultural Communication (Eds.), Language Teaching in the Member States of the European Union (Lingua). Paris: University of Sorbonne.

Moeller, A. J, \& Faltin Osborn, S. R. (2014). A Pragmatist Perspective on Building Intercultural Communicative Competency: From Theory to Classroom Practice Foreign Language Annals, 47(4), 669-683.

Mohan, B. A. (1986). Language and Content. Reading, MA: USA. Addison-Wesley.

Nation, I. S. P., \& Macalister, J. (2010). Language Curriculum Design. ESL \& Applied Linguistics Series. New York: USA. Routledge.

Prabhu, N. S. (1987). Second Language Pedagogy. Oxford: UK. Oxford University Press.

Roegiers, X. (2010). Una pedagogía de la integración: Competencias e integración de los conocimientos en la enseñanza. Colab. Jean-Marie De Ketele; trans. Juan José Utrilla. México: Fondo de Cultura Económica.

Saito, K., \& Hanzawa, K. (2016). Developing Second Language Oral Ability in Foreign Language Classrooms: The Role of the Length and Focus of Instruction and Individual Differences. Applied Psycholinguistics, 37, 813-840. https://doi.org/10.1017/S0142716415000259

Serna Dimas, H. M., Quaroni, E., Treuholz, T., Berlincourt, G., Franco, C. A., \& Sachett, D. (2016). Comunicación Intercultural en el Mundo Globalizado y la Formación Multicultural y Multilingüe de los Profesionales en Lenguas Modernas. Bogotá, Colombia. Ediciones EAN.

Serna Dimas, H. M. (2017). Instructional Design on Intercultural Communicative Competence at Universidad EAN. (Working Papers on ICC).

The New London Group. (2000). A pedagogy of multiliteracies: designing social futures. In B. Cope, \& M. 
Kalantzis (Eds.), Multiliteracies: literacy learning and the design of social futures (pp. 9-37). (London, Routledge).

Van Dijk, T. (2009). Society and Discourse. How social contexts influence text and talk. Cambridge: U.K. Cambridge University Press. https://doi.org/10.1017/CBO9780511575273

Widdowson, H. G. (1990). Aspects of Language Teaching. Oxford: UK. Oxford University Press.

Zull, J. E. (2002). The Art of Changing the Brain: Enriching the practice of teaching by exploring the biology of learning. Virginia: USA. Stylus.

\section{Copyrights}

Copyright for this article is retained by the author(s), with first publication rights granted to the journal.

This is an open-access article distributed under the terms and conditions of the Creative Commons Attribution license (http://creativecommons.org/licenses/by/4.0/). 